\title{
ASPECTOS MERCADOLÓGICOS DE PRODUTOS FLORESTAIS NÃO MADEIREIROS - ANÁLISE RETROSPECTIVA
}

\author{
Dalvo Ramires Balzon ${ }^{1}$ \\ João Carlos Garzel Leodoro da Silva² \\ Anadalvo Juazeiro dos Santos ${ }^{3}$
}

\begin{abstract}
RESUMO
O objetivo desse trabalho é analisar as características e o sistema de mercado de alguns dos principais produtos florestais não madeireiro nas regiões do RESEX Chico Mendes no Estado do Acre e do Centro Sul do Estado do Paraná, mais precisamente nos municípios de Guarapuava e Bituruna. A pesquisa surge da necessidade de mudanças nas atuais perspectivas de desenvolvimento florestal, ainda que estão limitadas em grande parte, à utilização de um único produto: a madeira. Com a utilização dos produtos florestais não madeireiros e com o aumento de sua relevância econômica e seu potencial de mercado criaram-se oportunidades para gerar renda e trabalho aos extrativistas e ao mesmo tempo compatibilizar com o manejo sustentado da floresta. Assim, torna necessária a implementação de medidas de regulamentação para promover o ordenamento do processo produtivo a partir de uma melhor compreensão e entendimento de sua cadeia produtiva, e de um novo modelo de regulação entre os diversos elos. A pesquisa foi realizada a partir de levantamento bibliográfico, entrevistas pessoais em pontos de distribuição e varejo na cidade de Curitiba, Paraná e questionário enviado "as instituições, entre os meses de janeiro à março de 2004.
\end{abstract}

Palavra-chave: Produtos florestais não madeireiros, extrativismo, sustentabilidade, mercado e futuro do setor

\section{ASPECTS MARKET OF NON-LUMBERMAN FOREST PRODUCT - RETROSPECTIVE ANALYSIS}

\begin{abstract}
The scope of this work is to analyse the characteristics and the market system of some of the principal nonlumberman forest products at RESEX Chico Mendes in Acre state and the South Centre of Parana state, more precisely in the districts of Guarapuava and Bituruna. The research is shown the need of changes but current perspectives of forest development, although they are largely limited to the use of an only product: the wood. Using the non-lumberman forest products, the increase in its economical relevance and potential market has grown the opportunities to produce income and work to the extractors and at the same time reconciled with the sustained handling of the forest. Therefore, it is necessary to implement the regular measures to promote ordering of the productive process with the better comprehension and understanding from its productive chain, and of a new regulation models among the several links. The research was accomplished from the bibliographical rising; personal interviews in the distribution points and retail trade in Curitiba, Paraná, and sent the institutions the questionnaire between January and March, 2004.
\end{abstract}

Keywords: non-lumberman forest products, extraction, sustainability, market and future of the sector

\section{INTRODUÇÃO}

O desenvolvimento do setor florestal no Brasil esteve basicamente associado à ocupação do solo para agricultura e pecuária, que neste processo colocava à disposição do mercado grandes quantidades de madeiras a custo baixo. $O$ processo inicia-se na Região Sul, com a utilização das florestas de
Araucária angustifólia, e tem-se repetido na Amazônia. Com o tempo, o conceito puro e simples de desenvolvimento econômico, segundo Ferreira e Viola (1996), "enfatizou a idéia de desenvolvimento sustentável, querendo dizer sustentabilidade econômica, ambiental e social". Assim, a questão da

\footnotetext{
${ }^{1}$ Prof. MSc das Faculdades SPEI. Doutorando Eng. Florestal - UFPR. Endereço: Rua Atílio Bório, 90. Cristo Rei. CEP 80050-250 E-mail dalvo.rb@terra.com.br

${ }^{2}$ Doutor em Economia e Política Florestal pela ESALC/USP e professor da UFPR no Departamento de Economia Rural e Extensão.

${ }^{3}$ Prof. Dr. do Departamento de Economia Rural e Extensão - UFPR
}

Recebido para publicação: 19/04/2004

Aceito para publicação: 22/09/2004 
sustentabilidade passou a ter um significado mais consistente, ou seja, "procedimento que se guiam pelas regras firmes da natureza, com seus métodos inteligentes de autorevelação e levando sempre em conta as questões sociais". E respeitando tais regras, segundo o referido autor passou a representar o reconhecimento, de que, para se ter desenvolvimento sustentável, alguns comportamentos econômicos convencionais devem ser abordados em favor de uma conduta mais equilibrada da sociedade em relação à natureza.

Planos de manejo de florestas naturais que concebam que este recurso se recupere entre explorações sucessivas e cuidadosamente planejadas são possíveis, mas na realidade quase inexistentes nas florestas tropicais do mundo. A prática ancestral, economicamente viável de extração dos PFNM, que mantém a estrutura e funcionalidade da floresta intacta, tem surgido como um meio capaz de harmonizar os papéis conflitantes das florestas tropicais. Esta prática chamou a atenção dos defensores e entusiastas das florestas tropicais de todo o mundo a partir dos anos 80 quando um movimento organizado de seringueiros no Brasil lutava para proteger suas terras contra a invasão dos criadores de gado (Borges e Braz,1998).

Segundo Santos et al, (2004), o termo "produtos não madeireiro da floresta" e termo similares como: "menores", "secundários" e "non-timber" (no sentido de madeira para construção), surgiu como expressões para o vasto aparato de produtos, animais e vegetais, que não se refiram à madeira derivada das espécies arbóreas da floresta. Podem ser coletados da floresta, produzidos como plantas semidomesticadas em plantios ou em esquemas agroflorestais, ou produzidos em graus variados de domestificação. $O$ seu "status" de selvagem ou semi domestificado os distinguem dos plantios agrícolas estabelecidos, tais como banana, mandioca ou café.

Beer \& Modermott (1989), citados por Mok (1991), definem produtos florestais não madeireiros como sendo todo o material biológico, exceto a madeira. De acordo com a classificação do Instituto Brasileiro de Geografia e Estatística - (IBGE), que utiliza o termo "produtos extrativos" da floresta, estes compreendem: borrachas; gomas não elásticas; fibras, oleaginosos; alimentícios; aromáticos e subprodutos da silvicultura. Assim, o presente artigo tem como objetivo analisar as características e o sistema de mercado de alguns dos principais produtos florestais não madeireiros nas regiões do RESEX Chico Mendes no Estado do Acre e do Centro Sul do Estado do Paraná, mais precisamente nos municípios de Guarapuava e Bituruna. A principal hipótese da pesquisa surge da necessidade de mudanças, mas atuais perspectivas de desenvolvimento florestal, ainda que estão limitadas em grande parte, à utilização de um único produto: a madeira.

\section{MATERIAL E MÉTODOS}

A metodologia utilizada foi baseada no Diagnóstico Rural Participativo - DRP(s) através de pesquisa participativa, levantamento bibliográfico, entrevistas pessoais e questionário enviado às instituições conforme Chambers, 1989. As entrevistas pessoais foram realizadas nos pontos de distribuição e varejo, na cidade de Curitiba-PR e as informações bibliográficas adquiridos de levantamentos junto ao IBGE (Instituto Brasileiro de Geografia e Estatística), Secretaria do Estado da Agricultura e Abastecimento dos Estados do Paraná, Acre e Amazonas, Embrapa, e de um Workshop "Manejo de Recursos Não Madeireiro - Perspectivas para a Amazônia" e o questionário foi elaborado com perguntas, visando a analise do processo de extração, mercado e perspectivas sobre o futuro do setor entre os meses de janeiro a março de 2004.

\section{RESULTADOS E DISCUSSÕES}

\section{Características do extrativismo dos PFNM}

No Brasil, a maior parte da população extrativista (que se mantêm com base na extração dos produtos florestais não madeireiros) são colonos, índios e seringueiros. De acordo com Borges e Braz (1998, p 8) os maiores problemas encontrados pelas famílias que extraem esses produtos são:

a) Desconhecimento das potencialidades do mercado;

b) Deficiência na organização comunitária; 
c) Deficiência no gerenciamento da produção e comercialização;

d) Deficiência no manejo e beneficiamento dos produtos, e

e) Distâncias de transportes.

A extração dos produtos florestais não madeireiros das reservas extrativistas abrange famílias que paralelamente fazem plantio agrícola em pequena escala e vendem seus produtos no comércio de cidades próximas à suas casas ou para intermediários, que compram no local da extração. Os problemas com transportes e o acesso até o local de extração são fatores que impedem uma melhor condição na comercialização dos produtos pelas famílias. $\mathrm{O}$ acesso às vezes leva dias $\mathrm{e}$ são feitos em rios e estradas sem pavimentação e conservação. A organização e o envolvimento comunitário como um todo ainda não é suficiente, faltando maior entrosamento e articulação, assim como há falta de capacitação técnica e ética das pessoas que atuam nos gerenciamentos dos bens das comunidades e de suas entidades. Com relação ao beneficiamento da matéria prima, impacta no sistema de extração e comercialização, e são influenciadas pela capacitação da mão de obra, pela distância e via de acesso, disponibilidade de energias, máquinas e equipamentos. (Ispn, 1997).

\section{Mercados}

Para os produtos florestais não madeireiros, a base do comércio assim como os grandes problemas ficam no interior da floresta, onde estão os agentes, que dão início à cadeia de comercialização. Esse comércio nessa área passa por questões históricas que se referem às relações entre os extrativistas, os intermediários, e os clientes nacionais e internacionais. $\mathrm{Na}$ base do sistema o preço de compra da mercadoria é baixo e normalmente os extrativistas ficam presos a um comerciante ou "patrão" pelos constantes endividamentos e ainda alguns problemas limitam as más condições sanitárias da produção, a instabilidade de demanda de mercado, a inconstância da produção e a falta de organização dos produtores para alcançar uma certa escala de produção (Rocha, 1996).
Para alguns produtos é necessário atingir padrões de acordo com normas de higiene e qualidade, como é o caso dos óleos de andiroba (Carafa guianesis), bacaba (Oenocarpus distichus) e castanha (Caryophilus aromaticus) que necessitam de equipamentos sofisticados e métodos de estabilização para atingir tais padrões (Cnpt, 1997). A instabilidade da demanda de mercado, a inconstância da produção e a falta de organização dos produtores para alcançar uma certa escalam de produção são alguns dos problemas encontrados pelos extrativistas. Segundo a Itto (1988), os esforços requeridos para viabilizar e obter sucesso na comercialização de produtos florestais não madeireiro seriam:

a) Maiores informações econômica e estatística;

b) Buscar estabelecer mercados mundiais;

c) Identificar o potencial de suprimento e padrão de qualidade destes produtos;

d) Desenvolver tecnologias de estocagem e transformação;

e) Desenvolver regulamentos de manejo e estudos de custos para os mesmos;

f) Buscar marketing adequado;

g) Criar o conceito de comercialização conjunta de vários produtos ao mesmo tempo, buscando o mesmo canal de comercialização.

Com relação ao mercado para os produtos florestais não madeireiros, as pesquisas revelam ser crescente o interesse dos consumidores além de ser ambientalmente correto. Estudos de mercado dos óleos naturais têm demonstrado que os óleos de copaíba (Copaifera multijuge), andiroba (Carafa guianesis), pimenta longa (Piper hispidivernium), pequi (Caryocar brasiliense Cam), ucuúba (Virola aurinamensis) e castanha (Caryophilus aromaticus) são utilizados pelas indústrias farmacêuticas e de cosméticos, bem como pelos estabelecimentos que vendem produtos naturais e farmácias homeopáticas. Entretanto, os que apresentam maior escala de comercialização são os (óleos de copaíba e andiroba e pimenta longa) sendo que os outros óleos citados são de 
comercialização restrita em lojas especializadas na venda de produtos naturais (Borges e Braz, 1998).

O óleo de copaíba apresenta propriedades medicinais, com uso popular em infecções, como cicatrizante e anti-séptico das vias urinárias. Tem utilidade ainda na indústria de cosméticos e de vernizes. Sua produção proveniente da decomposição das paredes das células no interior do tronco da árvore, aumentando-se internamente em cavidades, em forma de bolsas no interior do tronco. É um liquido insolúvel em água, de coloração amarelo-alaranjada ou castanha e de sabor amargo (Borges e Brás, 1998).

Ferreira (1999), em trabalho sobre o potencial de extração e comercialização do óleo-resina de copaíba na Floresta Estadual do Antimari - AC (FEA), utilizando uma metodologia alternativa de extração, atualmente utilizada pelos extrativistas, calculou os custos de produção e o retorno comercial da extração, o potencial de produção, bem como a eficiência do processo e situação de mercado para o óleo de copaíba no Estado do Acre. O resultado foi que na estação da seca, um maior número de árvores estão em atividade, aumentando o volume total de óleoresina e a produção média por indivíduo, que passa de 1,4 litros/árvore na estação intermediária, para 2,4 litros/árvore na estação seca. Assim, o retorno financeiro para as famílias da FEA alcançou margem bruta maior. Calculando o preço mínimo praticado na região em 1998 (US\$ 3,93/litro), na extração com mão de obra de terceiros, o retorno é de $12 \%$. Com a utilização da mão de obra familiar, essa eficiência se elevou para 48\%. Para uma família na FEA obter um retorno de $50 \%$ na venda de cada litro de óleo de copaíba, Ferreira (1999) afirma ser necessário um aumento no preço de comercialização do produto, o qual justifique o desenvolvimento da atividade.

Com relação ao óleo de andiroba, Rocha (1996) comenta que este pode ser substituído por outros produtos de outras espécies, além de ser de fácil fabricação sintética. Este fato tem levado o declínio de seu preço. Testes preliminares recentes mostram que as características do óleo de andiroba são comparáveis a dos óleos animais atualmente utilizados em aditivos de lubrificação e de fluido de corte de metais. O mercado para este óleo é predominantemente nacional e mesmo regional. A produção artesanal de sabonetes, cremes e xampus têm consumido a maior parte da produção nacional e eventuais exportações são feitas para a Europa, Canadá e Estados Unidos em pequenos volumes.

Outra espécie fornecedora de óleo é as Pimentas Longas, que vem ganhando atenção comercial. É um arbusto com características de plantas daninhas que os agricultores costumam cortar. O óleo extraído é o Safrol, muito utilizado na fabricação de inseticidas biodegradáveis, cosméticos e produtos farmacêuticos. A Embrapa vem desenvolvendo pesquisas com esta espécie e iniciou um projeto piloto em Vila Extrema (RO) onde os produtores irão coletar em torno de 5 toneladas de matéria prima estimando-se um rendimento de 250 litros. Cada litro de Safrol pode atingir preços de cerca de US\$ 6,00 no mercado externo e pode gerar um lucro de US\$ 1,5 mil por hectare (Rocha 1996).

Já com relação às ervas e plantas da Amazônia, com aplicação nas áreas medicinais e de cosméticos, cada vez mais tem aumentado $\mathrm{o}$ interesse da indústria farmacêutica. A exploração comercial dessas plantas apresenta perspectivas promissoras de se tornar uma atividade econômica rentável. $\mathrm{O}$ setor tem crescido todo ano, se profissionalizando e criando emprego e renda para o ribeirinho e caboclo, melhorando a qualidade de vida das pessoas que lidam diretamente com a coleta, armazenamento e venda de plantas medicinais e atuando com extrativismo planejado.

Segundo informações do INPA (Instituto Nacional de Pesquisas da Amazônia) cerca de 300 plantas nativas e introduzidas no mercado e catalogadas, têm potencial para as áreas medicinais, fototerápicas, aromáticas e de cosméticos. "O que falta é operacionalizar a produção local de medicamentos e cosméticos com a utilização de plantas amazônicas". Entre as espécies mais conhecidas, inclusive internacionalmente estão a unha-de-gato (Uncaria tomentose), alfavaca (Ocimum basilicum), catuaba (Erythroxylum catuabe), cubiu (Solanum sessiflorum), etc. De acordo com dados das instituições de pesquisa da região, cerca de cinco mil, dentre as $25 \mathrm{mil}$ espécies existentes na Amazônia Brasileira e 
Internacional, já estão catalogadas e com suas propriedades conhecidas.

No entanto, alguns mercados exigem que os produtores registrem a produção, e para isso é necessário que tenham a nomenclatura botânica oficial, laudo de identificação, descrição de método de cultivo e colheita, características organolépticas, pesquisas contaminantes, testes de pureza, analise qualitativa e quantitativa dos principais ativos quando conhecidos e a análise fotoquímica qualitativa dos componentes dos produtos (Shorr, 1997).

No centro sul do Estado do Paraná nos municípios de Guarapuava e Bituruna, entre os produtos florestais não madeireiros, destacamse o Xaxim (Dicksonia sellowiana), Pinhão (Araucária angustifolia), Erva mate (Ilex paraguariensis), os produtos medicinais, aromáticos dentre outros. No caso do Xaxim, a indústria normalmente é composta por galpão, sem máquinas especiais e utilizado principalmente mão-de-obra feminina. A estrutura comercial é relativamente simples, pois é uma planta nativa cujo exploração é extrativista, iniciando com o corte da planta, em seu habitat natural, daí transportado aos locais de confecção dos produtos. Já dentro do galpão, o tronco é cortado em formato padrão de vaso ou em forma de estacas ou, ainda, placas. Após a confecção, os produtos são agrupados por tamanho, embalados e etiquetados, estando prontos para serem vendidos no mercado, (Santos, Chotquis e Mielke, 2001). A comercialização dos artefatos de Xaxim para o consumidor final e realizado pôr inúmeros estabelecimentos varejistas, de pequeno, médio e grande porte, integrantes na economia formal e informal e os consumidores são de todas as classes sociais, entre eles estão os decoradores, jardineiros, construtoras, orquidófilos, floricultores, etc.

O mercado de Erva-mate é muito restrito à região sul do Brasil, sua produção é basicamente proveniente do extrativismo e, é o que goza do melhor padrão tecnológico entre os produtos florestais não madeireiros, com articulações entre os diferentes segmentos que integram a cadeia produtiva, com marketing organizado partindo do estudo dos consumidores como indivíduos e da demanda coletiva atua de modo integrado para obtenção dos objetivos empresariais de médio e longo prazo, por meio de satisfação dos consumidores. Com certificação de controle de qualidade, através do selo de qualidade da empresa e desenvolvimento de novos produtos, a indústria da Erva-mate, tem investido junto aos proprietários do setor ervateiro, constituindo em procedimentos fundamentais para o sucesso da atividade em todo o elo da cadeia. (Mazuchowski, Bracht e Maccari Junior, 2000). Para prevenir riscos sanitários, garantir padrões de qualidade e preservar as áreas com Erva-mate, a atual legislação pertinente para o processamento industrial e comercialização, normatiza desde a área produtiva até atingir o consumidor final, sendo determinada pelo Ministério da Saúde, Ministério da Fazenda, Instituto Brasileiro do Meio Ambiente e Recursos Naturais Renováveis (IBAMA), Secretaria de Estado da Agricultura e do Abastecimento.

Com relação ao Pinhão segundo a Secretaria da Agricultura e do Abastecimento do Paraná (1998), o fluxo de comercialização caracteriza-se essencialmente pelo baixo grau de industrialização e este fato deve-se basicamente por aspectos culturais e às restrições da sazonalidade e quantidade produzida do produto. $O$ fluxo inicia na propriedade, com a coleta da semente, a qual pode ter quatro destinos: centros de abastecimento, intermediários, varejo e consumidor. A partir dos centros de abastecimento, o pinhão pode ser direcionado para outros intermediários ou para a rede de varejo que podem mandar o produto de volta para outros centros de abastecimento, intermediários ou diretamente para o consumidor.

Os intermediários desempenham um importante papel na cadeia produtiva do Pinhão, principalmente em localidades onde a produção é pequena, inviabilizando o transporte pelos produtores para os centros de varejo, onde podem ser alcançados maiores valores ao produto Já os atacadistas, compram o Pinhão dos intermediários e vendem aos varejistas e daí para o consumidor final, que consomem arraigados a fatores culturais dos estados do Sul e Sudeste do país. É imprescindível a presença do pinhão nas festas juninas ou nas feiras de inverno.

Quanto à produção e o mercado de produtos medicinais, configura-se como um 
setor diversificado, a ponto de incluir temperos e plantas aromáticas. Os principais produtos são os que têm origem na aroeira (Alorus alba L), cabreúva (Aspidosperma subicanum), cambará (Moquinia polymorpha), caroba (Carduus benedictus), cedro (Cedrela odorata $L$ ), guaçatunga (Casearia silvestris $S w$ ), jequitibá (Cariniana estrellensis), pata de vaca (Bauhinia forficata Link) e sassafrás (Ocotea pretiosa). Analisando os dados do DESEX (Departamento de Comércio Exterior), permitiu verificar que existe grande mobilidade neste tipo de mercado e evidencia um setor em expansão, com boa parte da produção comercializada com o mercado externo. No Brasil as firmas que mais participam desse mercado estão localizadas em São Paulo.

Stridsberg, (2001, p.51), afirma que o mercado de produtos medicinais da floresta esta dividida em quatro níveis, segundo as quantidades comercializadas e o grau de transformação dos produtos. São eles:

a) Os coletores ou mateiros que são os fornecedores do mercado atacadista;

b) Os atacadistas que podem ser copiadores/distribuidores e laboratórios;

c) Os varejistas, tais como as farmácias de manipulação, homeopáticas ou naturalistas, os comércios fracionadores simples que vendem ao consumidor final, ou no atacado para revendedores de feira;

d) Feirantes de rua como último fornecedor e o quarto elo da cadeia.

Portanto o consumidor final tem várias opções de compra: farmácias, varejistas e feirantes e para cada caso é diferente o grau de transformação do produto, preço $\mathrm{e}$ apresentação.

Na primeira etapa do elo da cadeia, ou seja, os coletores ou mateiros os preços pagos pelo consumidor final no extremo da cadeia de transformação e distribuição é extremamente baixo, e há uma enorme diferença entre os preços praticados pelo mesmo produto no mercado interno.

No segundo nível da cadeia, ou seja, entre os distribuidores de folhas ou casca a granel, as vendas são feitas por quilo e os compradores são de vários tipos, e as diferenças entre os preços mínimos e máximos registrados, refletem variações importantes apenas para três produtos, Casca de Aroeira, Folha de Cariba e Folha de Guaçatunga.

No terceiro nível situam-se os varejistas locais, farmácias de manipulação, homeopáticas ou naturais e os comércios fracionadores simples que vendem no varejo ao consumidor final, ou no atacado para revendedoras de feira. Os preços dos produtos nesse nível da cadeia são extremamente variáveis, o que demonstra a imperfeição deste mercado (sem transparência), sendo que os maiores preços são observados na venda dos extratos.

Para os feirantes, o último integrante da cadeia de distribuição, tanto as quantidades vendidas, quanto os preços são reduzidos. A apresentação dos produtos são simples e vendidos ao consumidor em pequenos pacotes de 10 a 30 gramas, em geral. Nesse processo de fracionamento, o preço do produto pode chegar até dez vezes maior que o preço de compra.

\section{Futuro do setor}

Pela ambigüidade do setor, é difícil responder aos desafios do futuro, pois ainda existe arraigada uma tradição de origem extrativista. Além disso, torna-se necessário tomar consciência que uma das primeiras medidas a adotar é conhecer a cadeia produtiva visando identificar concorrências, sinergias e associações de objetivos complementares, em vista da globalização da economia como um todo. Como característica o setor tem a missão de gerar o seguinte:

a) Produtos competitivos, com qualidade e custos acessíveis internacionalmente, com a criação de valor para os indivíduos, empresas e nação, em um regime ambientalmente aceito e desejável;

b) Ter visão de negócios amplamente diversificada para atender os mercados externo e doméstico em crescimento, fazendo valer condições excepcionais de vantagens competitivas;

c) Previsão de cenário que contempla que o setor será regido por florestas plantadas e reciclagem de materiais de madeira e não madeira. 
Quanto às oportunidades, parecem claras em especial, às ligadas ao rápido crescimento de diferentes espécies e ao custo competitivo de extração e estabelecimento de floresta. Por outro lado, os pontos fracos estão concentrados nas tradições de políticas macroeconômicas de pouca confiabilidade, tais como: dívida social, conflitos agrários e boicote internacional a produtos proveniente de região cuja degradação ambiental tem atingido o meio ambiente.

Há necessidade de considerar o grande número e a origem dos produtos florestais não madeireiros, como o caminho para se buscar o desenvolvimento de modelo de manejo de uso múltiplo, de acordo com condições específicas de cada área extrativista, devendo haver uma política de incentivos específicos para promover esse desenvolvimento. Esse conceito está intimamente ligado com o plano de uso da terra (Leuschner, 1992). Nesse caso considerase toda a alternativa possível de possibilidades de administração dos recursos da floresta, como produtos florestais não madeireiros em conjunto, produção de alimento, turismo, proteção da vida silvestre, água, etc. Com o aumento da população associado à melhoria de renda, produzirá maior demanda por produtos florestais não madeireiro e a atividade industrial.

Segundo Vilela (1995, p.14) deve-se considerar que "no ambiente de sua operação existe uma relação progressiva entre ambiente e produto". A questão é que os valores sociais estão associados a uma utilização de produtos florestais não madeireiros relacionados a um melhor padrão de comportamento ambiental. No entanto, cabe destacar que os problemas ambientais não deixam de ser uma oportunidade para o setor, pois a conservação e a preservação devem caminhar junto com a existência das tecnologias, do interesse econômico e com a busca de produtos de alta qualidade com preservação ambiental.

No que tange ao mercado nacional, a abordagem de influência dos aspectos ambientais passa necessariamente por uma análise da situação internacional, onde existe uma crescente preocupação com aspectos ambientais e que tem afetado o mercado, principalmente nos países mais desenvolvidos. $\mathrm{O}$ rápido desdobramento dos fatos tem gerado preocupação nas relações comerciais entre países resultando em muitas pressões, e com isso vem desenvolvendo e implementando sistemas de verificação de qualidade ambiental dos produtos colocados no mercado.

No Brasil, com o advento da globalização, a abertura comercial de um lado trouxe a necessidade de se cuidar mais do meio ambiente e dos produtos florestais em geral, mas por outro lado, dado a tradição predatória dos recursos naturais, o mercado tem trazido uma situação de preocupação. $O$ que se percebe é que a economia ainda se beneficia muito pouco dos negócios de produtos florestais não madeireiro, principalmente na base da produção.

Relacionar a gestão ambiental com o desenvolvimento dos agroflorestais sustentado com as pressões dos consumidores e da sociedade em geral nos próximos anos, muito provavelmente poderá ser uma das prioridades do mercado. O manejo e a conservação da base de recursos naturais e a orientação da mudança tecnológica e institucional de maneira a assegurar a obtenção e a satisfação contínua das necessidades humanas para as gerações presente e futura na exploração florestal resultam no fato de não degradar o ambiente $\mathrm{e}$ ser tecnicamente apropriado, economicamente viável e socialmente justo. Isso envolve mudanças de paradigmas com base para elaboração de projetos sustentados, com avaliações prévias de impactos de interferências nos meio ambiente, pois mais do que gerar negócios, os produtos florestais têm também importante papel dentro do ecossistema. Assim não restam dúvidas de que as restrições ambientais também trazem novas oportunidades, e da análise do quadro exposto ficam identificadas que $\mathrm{o}$ mercado para $\mathrm{o}$ futuro, será ascendente, não só pelo fato do Brasil estar buscando o ponto satisfatório ambientalmente, mas, sobretudo pela disponibilidade de recursos (matéria prima) e a formação dos outros agentes produtivos em todo o país.

\section{CONCLUSÕES}

A grande dificuldade de elaborar trabalhos sobre a atividade extrativista de produtos florestais não madeireiros reside na quase completa ausência de dados, principalmente estatísticos, que mostram a 
quantidade produzida, comercializada e consumida de cada um dos principais produtos. A falta de recursos ou até mesmo a resistência nas informações fazem com que os pesquisadores deixem de elaborar trabalhos sobre o assunto.

A atividade tem que buscar o equilíbrio entre a produção econômica e a conservação da floresta, mediante a melhoria da qualidade geral das operações de extração, preservando e conservando os recursos naturais e ao mesmo tempo mantendo trabalho e renda aos extrativistas. Formada por famílias com baixa escolaridade e quase sempre sem nenhuma instrução quanto a mercados, tecnologias e recursos financeiros, são levadas a vender sua produção a preços baixo para intermediários (comerciantes local), ou para "marreteiros", que são pessoas que adentram ao interior da floresta para adquirir os produtos, mantendo-as dependentes $\mathrm{e}$ as impede de fazerem investimentos no setor.

Para o futuro, com o aumento das pesquisas e da renda, poderá produzir mais demanda e a atividade industrial deve gerar transferências de tecnologias e renda as famílias extrativistas, criando oportunidades. Assim, certamente fará com que a economia do setor cresça e melhore as condições financeira e tecnológica dos extrativistas além de novos atores buscarem nessa atividade o seu negócio, podendo crescer o comércio, tanto nacional quanto internacional contribuindo para a geração de mais trabalho e renda.

\section{REFERENCIAS}

BORGES, K H e BRAZ, E M. Recursos Florestais não madeireiros, versão preliminar do Workshop "Manejo de recursos não madeireiros - perspectivas para a Amazônia".Rio Branco, AC, Junho/98.

CHAMBERS, R. Notas e reflexões sobre o seminário "Agricultura e pesquisa agrícola: métodos complementares" In:

RICHARDS, P; BOX. L Agricultores experimentadores e pesquisa. Rio de Janeiro: PTA, 1989. P.5-15.

CHERKASOV, A., 1988. Classification of nom-timber resources in the USSR. In: Acta Bot. Fennica, 136: 3-5. Helsinki.
CNPT, 1997. Óleos e resinas podem ser novas alternativos econômica. Extrativismo na Amazônia. Boletim n. ${ }^{\circ} 2$. Dezembro de 1997, p.6.

CNPT: EMBRAPA. Recursos florestais não madeireiros. Documento preliminar de apoio ao Workshop "Manejo de Recursos Não Madeireiro. Rio Branco, 1998".

FERREIRA, L. A Potencial de extração e comercialização de óleo-resina de copaíba (Copaifera spp): Um estudo de caso na Floresta estadual de Antimari, Acre. Rio Branco: UFAC/PROPEG, 1999. Dissertação (Mestrado em ecologia e Manejo de Recursos naturais) - Pró-Reitoria de Pesquisa e PósGraduação, Universidade Federal do Acre, 1999. 64p.

FERREIRA, L. C e VIOLA, E. Incertezas da sustentabilidade na globalização. Campinas SP: Editora da UNICAMP, 1996. 234 p.

HOMMA, A. K. A Viabilidade econômica da extração de produtos florestais não madeireiro. Embrapa Amazônia Oriental. Belém Pará. Brasil, 2001.

IBGE Sistema IBGE de Recuperação Automática - SIDRA 97. ISPN, Relatório final: Sistematização de informações cadastrais das reservas extrativistas Chico Mendes. Rio Ouro, Rio Cajari e Alto Juruá, Brasília, DF. Dezembro, 1997.

ISPN - Relatório final: Sistematização das informações cadastrais das reservas extrativistas Chico Mendes. Rio Ouro Preto, Rio Cajarí e Alto Juruá. Brasília, DF. Dezembro, 1977.

ITTO. The Case for Multipll-use Management os Tropical Hardwood Forests. Harvard University Cambridge. Massachusetts. 1988.

JORNAL FOLHA de SÃO PAULO. São Paulo, vários números.

LEUSCHNER, W.A. Introduction to forest resource management. Florida, Krieger Publishing Company, 1992. 238p.

MAZUCHOWSKI, J. Z. BRACHT, M. J. e MACCARI JUNIOR, A. (org) Câmara setorial da cadeia produtiva da Erva-Mate do Paraná. MCT/CNPq/PROJETO PADCT 
Erva-Mate. Patentes industriais e as prioridades para os investimentos tecnológicos na cadeia produtiva da Erva-Mate. Curitiba PR, 2000. 178p.

MOK, S. T., 1991. Production and promotion of non-wood forest products. In: ? 103-111.

ROCHA, E. Padrões de distribuição espacial de três espécies de palmeiras com potencial econômico - Açaí (Euterpe precatória). Patauá (Oenocarpus bataua) e Bacaba (Oenocarpus mapora) na Reserva Extrativista Chico Mendes (informações PZ/UFAC), 1996.

SANTOS, A. J et al. Produtos não madeireiros: Comercialização, classificação, valoração e mercados. Curitiba, 14 p. Revista Floresta, 2003.

SANTOS, A. J. CHOTGUIS, J e MIELKE, E. Análise da cadeia produtiva do Xaxim (Dicksonia sellowiana) no Estado do Paraná. Curitiba PR, Julho/2001.
SCHORR, M. 1977. Relatório final da primeira etapa do projeto de comercialização CNPT/IBAMA/MMA e Associação de produtores da reserva extrativista Chico Mendes - Estado do Acre - Brasil. Brasília, DF.1977. 80p.

SECRETARIA DE AGRICULTURA E DO MEIO AMBIENTE DO PARANÁ. Boletim informativo agropecuário. Curitiba, 1998.

STRIDSBERG, I. H. C. Produção agroflorestal sustentável: Estudo de caso em pequenas propriedades no litoral paranaense. 2001132 p. Tese (Doutorado em Engenharia Florestal) - Programa de Pós Graduação em engenharia Florestal. Universidade Federal do Paraná. Curitiba.

WICKENS, G. E., 1991. Manegement issues for development of non-timber forest products. In: Unasylva, 42(165): 3-8.

VILELA, Ademar Filho. A cadeia produtiva é desconhecida. Revista Madeira. Ano IV edição n. ${ }^{\circ}$ 22, maio/1995, p. $11-14$. 